\title{
Climatic controls on mountain glacier basal thermal regimes dictate spatial patterns of glacial erosion
}

\author{
Jingtao Lai ${ }^{1,2}$ and Alison M. Anders ${ }^{1}$ \\ ${ }^{1}$ Department of Geology, University of Illinois at Urbana-Champaign, Urbana, IL 61801, USA \\ ${ }^{2}$ GFZ German Research Centre for Geosciences, Potsdam, 14473, Germany
}

Correspondence: Jingtao Lai (lai@gfz-potsdam.de)

Received: 17 March 2021 - Discussion started: 31 March 2021

Revised: 21 June 2021 - Accepted: 7 July 2021 - Published: 2 August 2021

\begin{abstract}
Climate has been viewed as a primary control on the rates and patterns of glacial erosion, yet our understanding of the mechanisms by which climate influences glacial erosion is limited. We hypothesize that climate controls the patterns of glacial erosion by altering the basal thermal regime of glaciers. The basal thermal regime is a first-order control on the spatial patterns of glacial erosion. Polythermal glaciers contain both coldbased portions that protect bedrock from erosion and warm-based portions that actively erode bedrock. In this study, we model the impact of various climatic conditions on glacier basal thermal regimes and patterns of glacial erosion in mountainous regions. We couple a sliding-dependent glacial erosion model with the Parallel Ice Sheet Model (PISM) to simulate the evolution of the glacier basal thermal regime and glacial erosion in a synthetic landscape. We find that both basal thermal regimes and glacial erosion patterns are sensitive to climatic conditions, and glacial erosion patterns follow the patterns of the basal thermal regime. Cold temperature leads to limited glacial erosion at high elevations due to cold-based conditions. Increasing precipitation can overcome the impact of cold temperature on the basal thermal regime by accumulating thick ice and lowering the melting point of ice at the base of glaciers. High precipitation rates, therefore, tend to cause warm-based conditions at high elevations, resulting in intensive erosion near the peak of the mountain range. Previous studies often assessed the impact of climate on the spatial patterns of glacial erosion by integrating climatic conditions into the equilibrium line altitudes (ELAs) of glaciers, and glacial erosion is suggested to be maximal around the ELA. However, our results show that different climatic conditions produce glaciers with similar ELAs but different patterns of basal thermal regime and glacial erosion, suggesting that there might not be any direct correlation between ELAs and glacial erosion patterns.
\end{abstract}

\section{Introduction}

Earth's past climate has left a clear imprint on the topography of mountain ranges worldwide. During the late Cenozoic, global cooling induced widespread glaciation and glacial erosion created unique landforms in mountainous regions, such as cirques, hanging valleys, and overdeepenings. Climate is a primary control on the pace and spatial variability of glacial erosion, and better constraint on this control is essential to improve understanding of the development of topography worldwide during the climate perturbations of the late Cenozoic. Recent compilations of modern glacial ero- sion rates have provided an empirical measure of the relationship between climate and glacial erosion (Cook et al., 2020; Koppes et al., 2015). Temporal evolution of glacial erosion rates inferred from sedimentary records also suggests that glacial erosion mostly occurs in some optimal climatic conditions (Fernandez et al., 2011; Ganti et al., 2016; Mariotti et al., 2021). Yet a process-based understanding of how climatic conditions influence the rates and patterns of glacial erosion is still limited. Intuitively, climate could influence glacial erosion by modulating the thermal structures of glaciers, because warm-based glaciers are much more powerful erosional agents than cold-based glaciers (Kleman and 
Glasser, 2007). We explore this idea by using numerical simulations to investigate the impact of climatic conditions on the basal thermal regime of glaciers and, consequently, the rates and patterns of glacial erosion.

Climatic controls on glacial erosion have often been assessed by integrating climatic conditions into the equilibrium line altitudes (ELAs) of glaciers. Previous studies have suggested that glacial erosion is most effective at or above the ELA of a glacier (e.g., Anderson et al., 2006; MacGregor et al., 2000). Numerical landscape evolution models that approximate the erosion rate as a function of sliding velocity also produce focused erosion near the ELA (e.g., Herman et al., 2011; MacGregor et al., 2000). In addition, the strong correlation between the mean or peak elevation of mountains and the ELAs of modern or past glaciers in some mid-latitude mountain ranges suggests that glacial erosion is concentrated near or above the ELA (Anders et al., 2010; Brozović et al., 1997; Egholm et al., 2009; Mitchell and Montgomery, 2006). However, the correlation between the ELAs and mountain heights breaks down in high-latitude mountain ranges because the cold-based glaciers at high elevations cause limited erosion, resulting in high mountain peaks that sit above the ELA (Thomson et al., 2010). Additionally, measurements of sediment production by modern glaciers reveal that the rates of glacial erosion vary as a function of latitude, which is an indication of the basal thermal regime (Koppes et al., 2015). These observations suggest that the basal thermal regime is a fundamental control on the rates and spatial patterns of glacial erosion and motivate us to consider the influence of climate on the basal thermal regime, rather than the ELA, as a primary control on glacial erosion.

The basal thermal regime is expected to exert first-order control on the spatial variability in glacial erosion. Basal sliding speed and meltwater pressure both strongly modulate the rate of glacial abrasion and quarrying (Hallet, 1979, 1996; Iverson, 2012) and are both controlled by the basal thermal regime. Below cold-based glaciers, the basal ice is frozen to the bedrock and limited basal sliding and meltwater supply cause minimal glacial erosion. In contrast, warmbased glaciers erode their beds via abrasion and quarrying due to active basal sliding and meltwater production. Under large continental ice sheets, the contrast in erosive power between cold-based and warm-based portions of the ice sheets has been suggested to have caused selective linear erosion of deep valleys and fjords along glaciated continental margins (Hall et al., 2013; Kleman and Glasser, 2007).

While polythermal glaciers that contain both warm-based and cold-based portions are common in mountainous regions, the influence of the basal thermal regime on the erosion of polythermal alpine glaciers has received little attention. Previous glacial landscape evolution models often neglected the basal thermal regime by assuming the glacier is entirely warm-based (e.g., MacGregor et al., 2000; Prasicek et al., 2018). A few studies have examined polythermal mountain glaciers and demonstrated that a cold climate may produce cold-based ice at high elevations (Anderson et al., 2012; Tomkin and Braun, 2002; Yanites and Ehlers, 2012). However, the glacier thermodynamics in these early glacial landscape evolution models is oversimplified. The basal temperature is approximated by using a one-dimensional column model that accounts for the vertical heat transportation and neglects the longitudinal component (e.g., Tomkin and Braun, 2002). Recent compilation of modern glacial erosion rates highlights the complex relationships between climate, glacier dynamics, and glacial erosion (Cook et al., 2020; Koppes et al., 2015). Therefore, a better approximation for the glacier thermodynamics is essential in glacial landscape evolution modeling. In our previous work (Lai and Anders, 2020), we built a landscape evolution model that includes a more sophisticated representation of thermodynamics (Aschwanden et al., 2012). Our previous focus was on how geothermal heat fluxes influence the basal thermal regime and glacial erosion. In this study, we use our glacial landscape evolution model with a thermodynamically coupled ice dynamics model to investigate the climatic control on the rates and patterns of glacial erosion through the basal thermal regime. We aim to explore the influence of precipitation and temperature on the spatial pattern of glacial erosion that arises through modulation of the basal thermal regime. We present a series of numerical simulations that allow us to assess the correlation between the basal thermal regimes of glaciers and the rates and patterns of sliding-driven glacial erosion under a range of climatic settings.

\section{Methods}

We build a landscape evolution model with the Parallel Ice Sheet Model (PISM, http://www.pism-docs.org, last access: 30 July 2021) to simulate the evolution of glacial landscapes. The approach we use in this study is similar to that presented in Lai and Anders (2020) where we first added glacial erosion to PISM. In this study, we extend the model presented by Lai and Anders (2020) by adding fluvial incision and bedrock uplift to the landscape evolution model. In this section, we briefly summarize the different components of our model.

\subsection{Ice flow model - Parallel lce Sheet Model}

To solve for ice flow, PISM uses a hybrid stress balance scheme that combines the shallow ice approximation (SIA; Hutter, 1983) for internal deformation and the shallow shelf approximation (SSA; Morland, 1987) for membrane stress (also known as longitudinal stress). The membrane stress is an important component in balancing the driving stress in alpine glaciers (Bueler and Brown, 2009; Hindmarsh, 2006). Basal sliding velocity is related to the basal shear stress through a Weertman-style sliding rule, and it is controlled by the balance between basal shear stress, membrane stress, and driving stress. Basal sliding velocity is also controlled by the amount of subglacial meltwater through a simple subglacial 
hydrology model. The conservation of energy is solved using an enthalpy-based scheme in PISM (Aschwanden et al., 2012). The governing equations of PISM are presented in Bueler and Brown (2009) and Winkelmann et al. (2011), and we refer readers to these works for a detailed description of the model.

PISM has been used to simulate the contemporary Greenland Ice Sheet, and the result shows a good correlation between modeled and observed ice surface velocity (Aschwanden et al., 2016). PISM has also been used to reconstruct the complex history of glaciation in mountainous regions (e.g., Golledge et al., 2012; Seguinot et al., 2018).

\subsection{Landscape evolution model}

The evolution of bedrock topography is controlled by glacial erosion, fluvial incision, and uplift. At each time step, bedrock topography is uplifted at a uniform and constant rate across the model domain. In areas where the thickness of ice is greater than $10 \mathrm{~m}$, only glacial erosion can change the topography, and in other areas, only fluvial incision is allowed to occur. We assume that all eroded materials are transported out of the model domain efficiently so that there is no deposition in the system.

\subsubsection{Glacial erosion model}

The rate of glacial erosion, $E_{\mathrm{g}}$, is modeled as a linear function of the sliding velocity, $\boldsymbol{u}_{\mathrm{s}}$ :

$E_{\mathrm{g}}=K_{\mathrm{g}}\left|\boldsymbol{u}_{\mathrm{s}}\right|$

where $K_{\mathrm{g}}$ is an erodibility coefficient. In this study, the value of $K_{\mathrm{g}}$ is 0.0001 in all simulations. This erosion model has been widely used in glacial landscape evolution models (e.g., Egholm et al., 2011; Herman et al., 2011; MacGregor et al., 2000; Tomkin and Braun, 2002; Yanites and Ehlers, 2012). Although available field measurements have suggested a nonlinear relationship between sliding velocity and glacial erosion rates (Cook et al., 2020; Herman et al., 2015; Koppes et al., 2015), we choose to use a linear erosion rule for simplicity, since our main goal is to investigate the influence of climate on the spatial patterns of erosion. This model is supported by theoretical studies of glacial abrasion (Hallet, 1979), and it is a reasonable approximation of glacial erosion when abrasion dominates glacial erosion (Humphrey and Raymond, 1994). Although glacial erosion by quarrying is complicated by the subglacial hydrological conditions (Hallet, 1996; Iverson, 2012), this sliding-dependent model still reproduces the qualitative patterns of glacial erosion from a numerical model driven by a quarrying law (Ugelvig et al., 2016). A common shortcoming of this sliding-based model is that steep bedrock slopes can produce unrealistically high erosion rates and trigger runaway effects (Herman et al., 2011). To avoid this, we do not allow bedrock slopes to exceed a threshold value of $45^{\circ}$. If the slope of bedrock topography reaches the threshold value, glacial erosion is prohibited.

\subsubsection{Fluvial incision model}

Fluvial incision is modeled using the stream power incision model (Whipple and Tucker, 1999). The rate of fluvial incision, $E_{\mathrm{f}}$, is a function of drainage area, $A$, and bedrock slope, S:

$E_{\mathrm{f}}=K_{\mathrm{f}} A^{m} S^{n}$,

where $K_{\mathrm{f}}$ is an erodibility coefficient and $m$ and $n$ are constants. $K_{\mathrm{f}}$ is a major unconstrained parameter in the stream power incision model (Harel et al., 2016). In this study, we choose to use a value of 0.00001 because it falls within the typical range of $K_{\mathrm{f}}$ used in many previous studies (e.g., Herman and Braun, 2008; Lai and Anders, 2018; Whipple and Tucker, 1999) and it predicts a reasonable fluvial relief in our simulations. The value of $K_{\mathrm{f}}$ is uniform across the model domain and constant over the glacial-interglacial cycle. The $m / n$ ratio is predicted to be $\sim 0.5$ by theory (Whipple and Tucker, 1999), and it is supported by global field observations (Harel et al., 2016). In our simulations, $m$ and $n$ are 0.5 and 1, respectively. Flow direction is approximated using the D8 algorithm, and the drainage area is calculated using the Fastscape algorithm (Braun and Willett, 2013). In our implementation, the drainage area includes upstream areas occupied by glaciers. In glaciated areas, the direction of water flow is determined based on ice surface elevation rather than bedrock elevation. Fluvial incision only applies to the areas outside of the glacial realm, and in glaciated areas, the rate of fluvial incision is set to zero.

Ideally, the fluvial incision model should reflect the influence of glacier meltwater and precipitation on fluvial incision. However, the goal of this study is to investigate the climatic controls on glacial erosion through the basal thermal regime, and incorporating a climate-dependent fluvial incision model could make it difficult to isolate the impact of climatic conditions on glacial erosion. Therefore, we simply model fluvial incision using the stream power incision law.

\subsection{Initial conditions}

The initial bedrock topography is a synthetic fluvial landscape created in the Landlab model platform (Hobley et al., 2017). The fluvial landscape is a $100 \mathrm{~km}$ by $100 \mathrm{~km}$ mountain range with $20 \mathrm{~km}$ wide piedmont plains on each side (Fig. 1a). The piedmont plains are removed in all figures for a clear illustration of the mountain range. The fluvial incision model used for creating the initial topography is the same as the model described in Sect. 2.2, and the value of the fluvial erodibility coefficient is also 0.00001 . The rate of uplift is $0.0035 \mathrm{~m} \mathrm{yr}^{-1}$. The uplift rate and fluvial erodibility coefficient used for creating the initial topography are maintained 

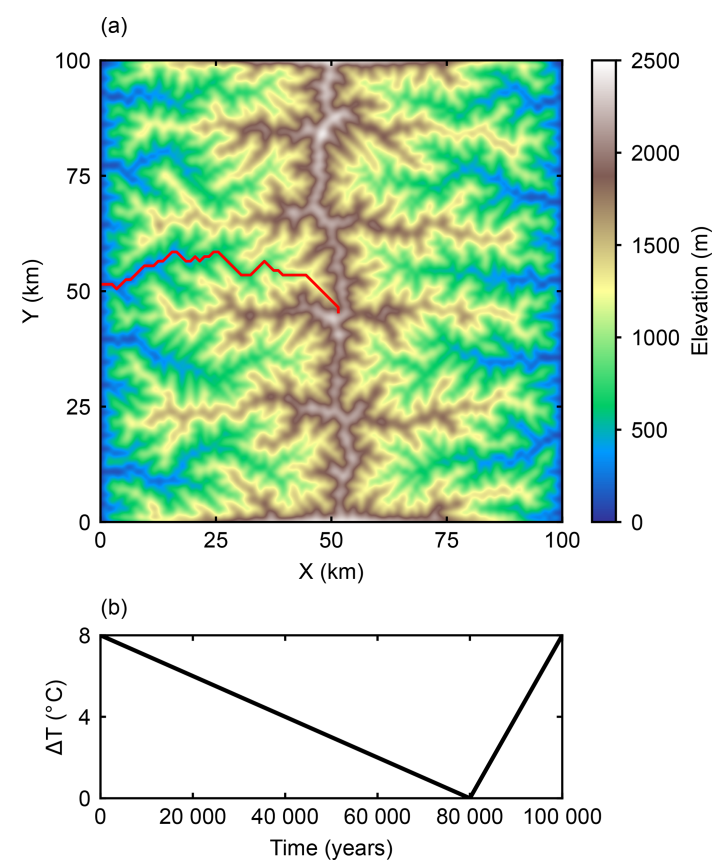

Figure 1. (a) The initial bedrock topography is a synthetic fluvial landscape, representing a typical pre-glacial setting. The piedmont plains are not shown in the figure for a clear illustration. The red curve indicates the valley profile shown in Fig. 4. (b) Cyclic climate forcing. The mean annual sea-level temperature decreases linearly for 80000 years and then rises for 20000 years. The magnitude of the temperature change is $8^{\circ} \mathrm{C}$. All simulations use the same cyclic climate forcing and the climatic conditions at glacial maximum (80000 years) are different in different cases.

in the subsequent glacial erosion simulations. Fluvial incision and rock uplift are in equilibrium in the initial topography such that the fluvial incision rate equals the rock uplift rate. The initial topography has a relief of $\sim 3000 \mathrm{~m}$, and the mountain range has five major valleys on each side. The grid resolution is $1 \mathrm{~km}$. This resolution is chosen because it provides a reasonable balance between accuracy and efficiency in PISM (Aschwanden et al., 2016).

All the simulations start from an ice-free topography. This is a reasonable initial state because in most cases the climate forcing only allows for a limited ice cover along the mountain ridges during the interglacial periods.

\subsection{Climate forcing}

Climate forcing is represented by the mean annual sea-level temperature and mean annual precipitation, and PISM takes these two parameters as input values to calculate the ice surface mass balance. Spatially, the mean annual temperature decreases as the elevation rises with a lapse rate of $6.5^{\circ} \mathrm{Ckm}^{-1}$, and the mean annual precipitation is uniform across the model domain. Temporally, the seasonal variation of temperature is modeled by a sinusoidal function with the summer temperature assumed to be $5{ }^{\circ} \mathrm{C}$ higher than the mean annual temperature. There is no seasonal variation in precipitation. A positive degree day (PDD; Calov and Greve, 2005) model then calculates the ice surface mass balance based on temperature and precipitation.

In all simulations, we use a 100000-year glacialinterglacial cycle with a "saw-tooth" variation of temperature (Fig. 1b). The mean annual sea-level temperature decreases by $8{ }^{\circ} \mathrm{C}$ linearly for 80000 years and then increases linearly for 20000 years. The mean annual precipitation increases by $7.2 \%$ for every $1{ }^{\circ} \mathrm{C}$ of increase in temperature (Huybrechts, 2002).

\subsection{Experiment design}

We explore the impact of climatic conditions on glacial erosion by varying the mean annual sea-level temperature and mean annual precipitation at the glacial maximum. The glacial mean annual sea-level temperature ranges from 1 to $5^{\circ} \mathrm{C}$, and the mean annual precipitation at glacial maximum ranges from 50 to $2000 \mathrm{~mm} \mathrm{yr}^{-1}$. In order to isolate the impact of basal thermal regime on glacial erosion from the influence of glacier extent and ELAs, we select different ranges of precipitation rates for different temperature values. For each temperature value, through trial and error, we first choose a proper precipitation rate that allows the glacier fronts to reach the edge of the mountains and then we explore a list of precipitation rates below this value. This allows us to conduct a group of simulations with similar ELAs. However, the range of precipitation for cold climates is small because cold climates produce large glaciers without significant amounts of precipitation. Therefore, we conduct an additional group of simulations with cold temperatures and high precipitation rates. The values of mean annual sea-level temperature and mean annual precipitation for all the simulations are summarized in Table 1.

For each climate condition, we not only examine the output of our landscape evolution model, but also consider the output from PISM over an unchanging topography. These glaciation-only cases isolate the impact of climate on the basal thermal regime because they avoid any feedbacks between evolving topography and the glacier basal thermal regime. All the parameters in the landscape evolution models including the glacial erosion coefficient, the stream power erosion coefficient, and the bedrock uplift rate are held constant in all the simulations. All the simulations are run over one 100000 -year glacial-interglacial cycle.

\section{Results}

In order to highlight the climatic controls on the basal thermal regime of glaciers and spatial patterns of glacial erosion, we first compare a set of models in which different climate conditions produce similar ELAs at the glacial maximum. Next, we compare the results of groups of simulations with 
Table 1. Climate conditions explored in this study.

\begin{tabular}{ll}
\hline $\begin{array}{l}\text { Mean annual sea-level } \\
\text { temperature at glacial } \\
\text { maximum }\left({ }^{\circ} \mathrm{C}\right)\end{array}$ & Mean annual precipitation at glacial maximum $\left(\mathrm{mm} \mathrm{yr}^{-1}\right)$ \\
\hline 1 & $50,100,150,200,250,300,350,400,450,500,600,800,1000,1200,1400$ \\
2 & $75,150,225,300,375,450,525,600,675,750,800,100,1200,1400$ \\
3 & $100,200,300,400,500,600,700,800,900,1000,1200,1400$ \\
4 & $150,300,450,600,750,900,1050,1200,1350,1500$ \\
5 & $200,400,600,800,1000,1200,1400,1600,1800,2000$ \\
\hline
\end{tabular}

different mean annual sea-level temperatures and the same mean annual precipitation rate at the glacial maximum to explore the sensitivity of the spatial pattern of glacial erosion to temperature. Finally, we compare the results of cases with different mean annual precipitation rates and the same mean annual sea-level temperature at the glacial maximum to investigate the influence of precipitation.

\subsection{Climatic controls on the basal thermal regime}

We begin by exploring the sensitivity of basal thermal regimes to climatic conditions by comparing results of glaciation-only cases in which landscape evolution models are not enabled. In order to isolate the impact of glacier sizes and ELAs on glacial erosion, we compare the results of three simulations with similar ELAs at the glacial maximum but different climatic conditions. Unsurprisingly, the basal thermal regimes of simulated glaciers are distinct in each case and strongly controlled by climatic conditions, despite the similarity in the ELA and ice extent across all the cases (Fig. 2). Different climatic conditions in the three simulations produce similar ELAs around $1300 \mathrm{~m}$ at glacial maximum. As a result, the modeled extent and thickness of ice at the glacial maximum is also similar in different cases (Fig. 2ac). The basal thermal regimes at glacial maximum, however, vary significantly as a function of climate despite the similar ice extent and thickness (Fig. 2d-f). In a cold and dry climate $\left(1^{\circ} \mathrm{C}, 400 \mathrm{~mm} \mathrm{yr}^{-1}\right)$, warm basal ice only occurs in major valleys, while glaciers at high elevations are mostly coldbased due to the cold temperature (Fig. 2d). As the climate transitions into warmer conditions, glaciers near the center of the range shift to warm-based conditions, and areas with warm basal ice extend into higher elevations (Fig. 2e). In the warmest climate $\left(5^{\circ} \mathrm{C}, 1600 \mathrm{~mm} \mathrm{yr}^{-1}\right)$ most of the glaciers are warm-based (Fig. 2f). The different basal thermal regimes have the potential for producing distinct glacial erosion patterns, as we will show in the next section.

In addition to the basal thermal regime, basal shear stress is another important control on basal sliding and, consequently, glacial erosion (Seguinot and Delaney, 2021). All the three simulations predict high shear stress along mountain ridges and in major valleys, and the spatial patterns of basal shear stress show much less variation between different climates than the patterns of basal thermal regime, especially in major valleys (Fig. $2 \mathrm{~g}-\mathrm{i}$ ).

\subsection{Spatial patterns of erosion controlled by basal thermal regime}

Having demonstrated that climate strongly influences the distribution of warm ice in the absence of erosion, we now implement glacial and fluvial erosion and rock uplift to compare the modeled glacial erosion in three cases with different climates but similar ELAs. We quantify the average basal thermal regimes over a glacial-interglacial cycle by calculating the percentage of time with warm-based conditions during a cycle. In all simulations, glacial erosion tends to focus in areas where the basal ice is mostly warm throughout the whole cycle (Figs. 3 and 4). In the case with a cold and dry climate $\left(1^{\circ} \mathrm{C}, 400 \mathrm{~mm} \mathrm{yr}^{-1}\right)$, glaciers are perennially coldbased at high elevations (Figs. $3 g$ and $4 d$ ), leading to limited glacial erosion at high elevations near the center of the range (Figs. 3d and 4a). Warm-based areas are mostly found in major valleys (Figs. 3g and 4d). During a glacial-interglacial cycle, middle parts of the valleys are influenced by warmbased glaciers for a longer period than lower parts of the valley (Figs. 3g and 4d) because the lower parts are only covered by glacial ice for a limited period during the coldest intervals. Consequently, most glacial erosion occurs in the middle parts of major valleys (Figs. $3 \mathrm{~d}$ and $4 \mathrm{a}$ ). In contrast, in a warm and wet climate $\left(5^{\circ} \mathrm{C}, 1600 \mathrm{~mm} \mathrm{yr}^{-1}\right)$, warm-based areas extend into higher elevations than in a cold and dry climate and glaciers are constantly warm-based at high elevations (Figs. 3i and 4f). The area with significant glacial erosion also migrates towards the center of the range at high elevations in a warm and wet climate (Figs. $3 \mathrm{f}$ and 4c).

The different spatial patterns of glacial erosion lead to distinct landforms in different climates. In a cold and dry climate, the glacial erosion rate exceeds the bedrock uplift rate in major valleys, producing overdeepenings and increasing local relief, while at high elevations, pre-glacial landforms are preserved under cold-based glaciers and a limited amount of erosion allows for an increase of the elevation of some peaks (Figs. 3a and 5a). In contrast, in a warm and wet climate, significant erosion at high elevations lowers the peaks and efficiently reshapes the topography near the center of 
$1^{\circ} \mathrm{C}, 400 \mathrm{~mm} \mathrm{yr}^{-1}$

(a)

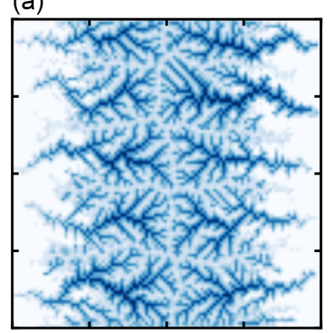

(d)
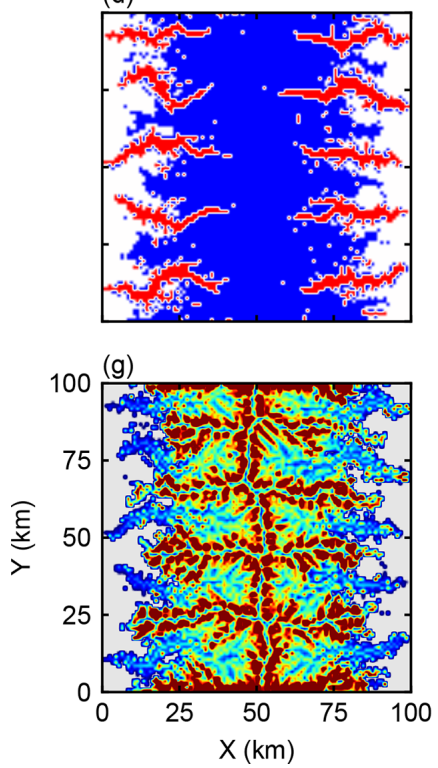

$3^{\circ} \mathrm{C}, 800 \mathrm{~mm} \mathrm{yr}^{-1}$

(b)

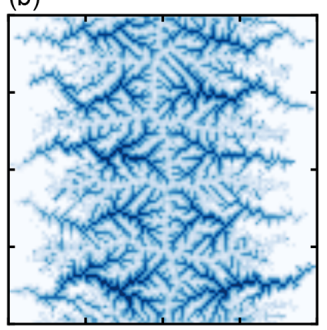

(e)

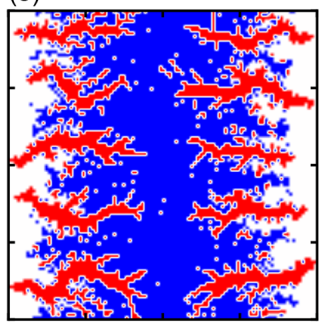

(h)

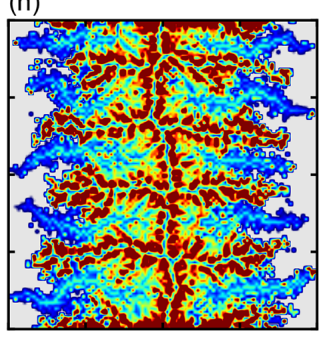

$5^{\circ} \mathrm{C}, 1600 \mathrm{~mm} \mathrm{yr}^{-1}$

(c)
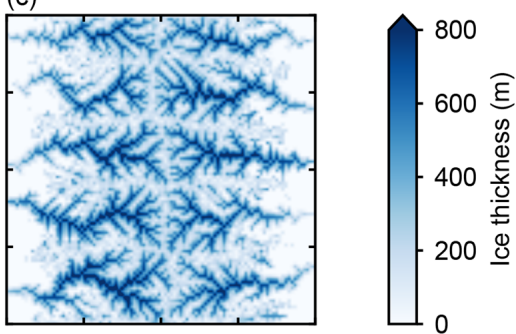

(f)
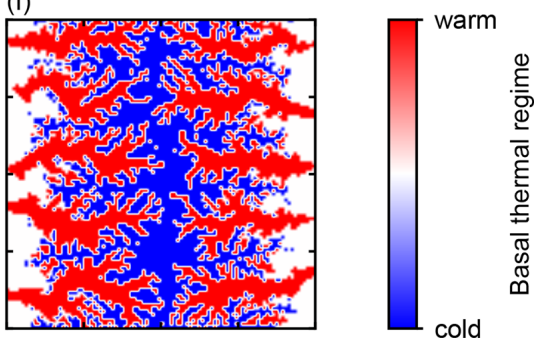

(i)
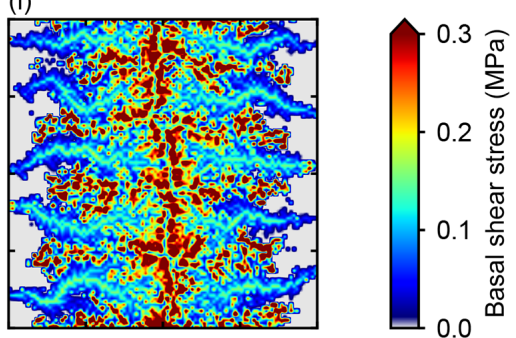

Figure 2. 2-D mapview of modeled ice thickness (a-c), basal thermal regime (d-f), and basal shear stress (g-i) at glacial maximum. The left column (a and d) is the case with a mean annual sea-level temperature of $1^{\circ} \mathrm{C}$ and a mean annual precipitation rate of $400 \mathrm{mmyr}$ at the glacial maximum, corresponding to a glacial ELA of $1300 \mathrm{~m}$. The middle column $\left(\mathbf{b}\right.$ and $\mathbf{e}$, glacial mean annual sea-level temperature $=3{ }^{\circ} \mathrm{C}$, glacial mean annual precipitation $\left.=800 \mathrm{~mm} \mathrm{yr}^{-1}\right)$ and right column $\left(\mathbf{c}\right.$ and $\mathbf{f}$, glacial mean annual sea-level temperature $=5^{\circ} \mathrm{C}$, glacial mean annual precipitation $=1600 \mathrm{~mm} \mathrm{yr}^{-1}$ ) are cases with warmer and wetter climate than the left column. These three climatic settings produce similar ELAs around $1300 \mathrm{~m}$ at glacial maximum.

the range, creating cirque-like landforms and overdeepenings near the peaks (Figs. 3c and 5c). Distinct landscapes caused by variation in basal thermal regimes are also reflected by changes in the hypsometry of the topography (Fig. 6). In a cold and dry climate, the relief of the mountain range is increased after a glacial-interglacial cycle, while the relief is decreased in a warm and wet climate, even when the ELAs at the glacial maximum are similar.

We have shown that the spatial pattern of erosion accumulated throughout an entire glacial cycle varies due to climatic effects on the basal thermal regime. Additionally, we observe that erosion rates at different stages during a glacial cycle also reveal the influence of climate on glacial erosion patterns through the basal thermal regime (Fig. 7). Early in the glacial cycle, all three climates predict limited ice cover at high-elevations near the center of the mountain range. However, the warm and wet case features much greater erosion rates than the colder and dryer cases (Fig. 7a and b), despite similar extents of ice cover. Similarly, at the glacial maximum, the spatial patterns of erosion are different under different climatic conditions (Fig. 7d-f) even though these climates produce glaciers with similar sizes. In a cold and dry climate, most erosion occurs at low elevations in major valleys (Fig. 7d), while a warm and wet climate predicts focused erosion at high elevations (Fig. 7f). During the deglaciation stage, the case with warm and wet climate has lower erosion rates than the other two cases (Fig. $7 \mathrm{~g}-\mathrm{i}$ ), because the topography is eroded and the size of glaciers is limited.

\subsection{Sensitivity to temperature}

Air temperature is one of the primary controls on the glacier basal thermal regime. We compare cases with different mean annual sea-level temperatures and the same precipitation rate at the glacial maximum. Unsurprisingly, the extent of glacia- 
$1{ }^{\circ} \mathrm{C}, 400 \mathrm{~mm} \mathrm{yr}^{-1}$

(a)

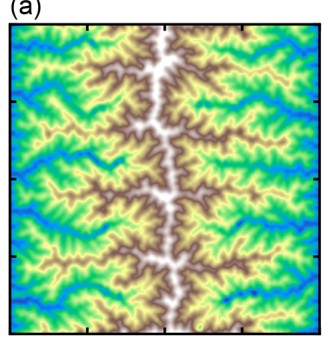

(d)
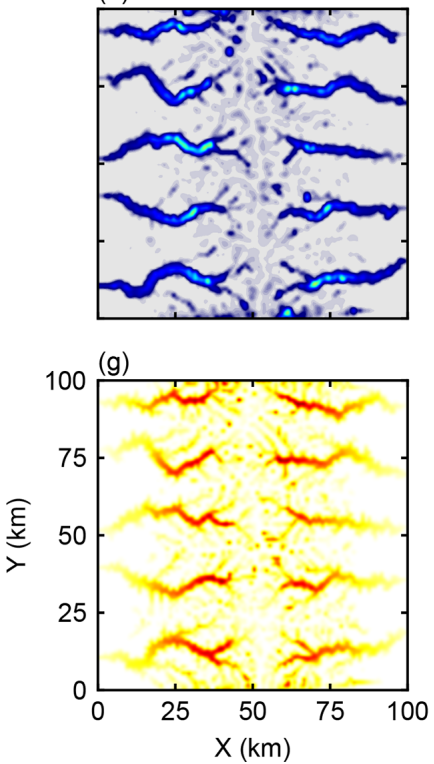

$3^{\circ} \mathrm{C}, 800 \mathrm{~mm} \mathrm{yr}^{-1}$

(b)

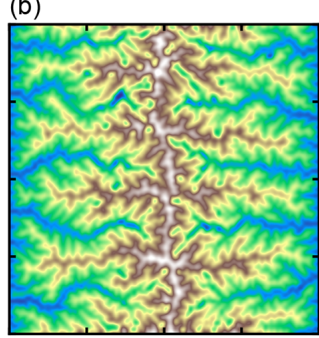

(e)

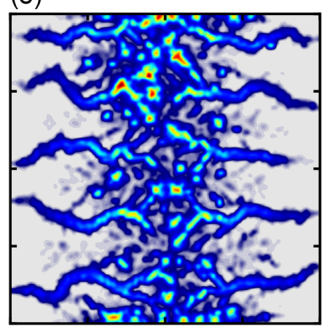

(h)

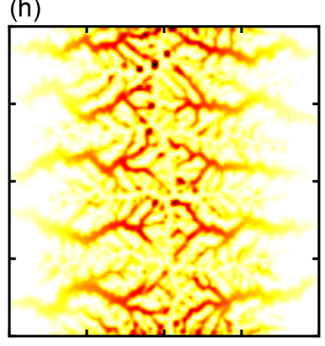

$5^{\circ} \mathrm{C}, 1600 \mathrm{~mm} \mathrm{yr}^{-1}$

(c)
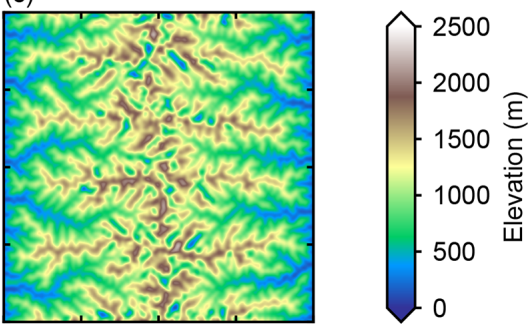

(f)
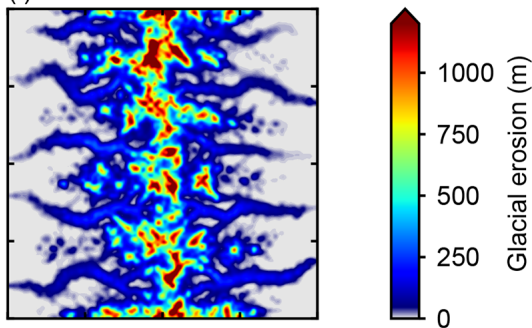

(i)

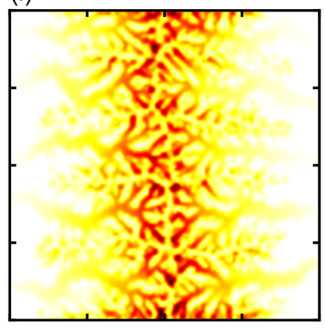

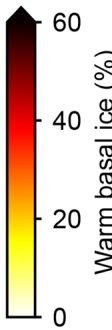

Figure 3. 2-D mapview of the modeled topography after a glacial-interglacial cycle (a-c), amount of glacial erosion (d-f) and percentage of time with warm basal ice $(\mathbf{g}-\mathbf{i})$. Each column represents model results for a specific climate. The three climatic settings produce similar ELAs around $1300 \mathrm{~m}$.

$1^{\circ} \mathrm{C}, 400 \mathrm{~mm} \mathrm{yr}^{-1}$
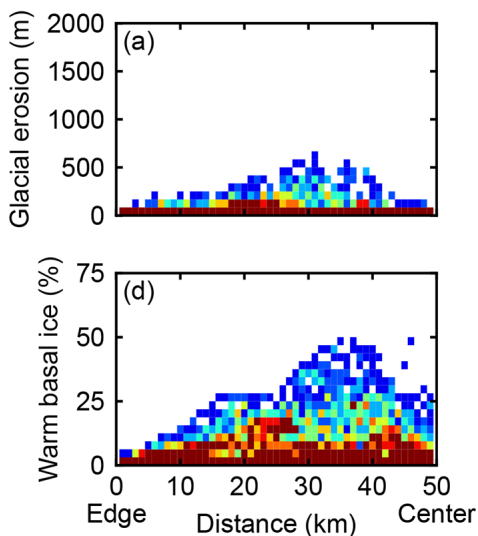

$3^{\circ} \mathrm{C}, 800 \mathrm{~mm} \mathrm{yr}^{-1}$
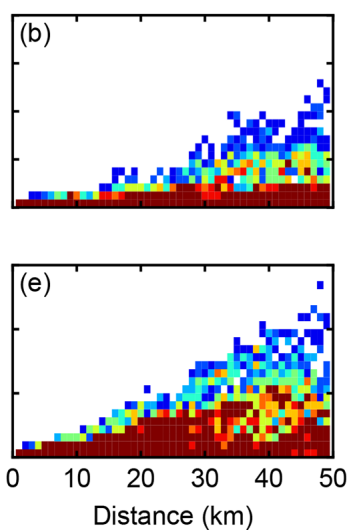

$5^{\circ} \mathrm{C}, 1600 \mathrm{~mm} \mathrm{yr}{ }^{-1}$
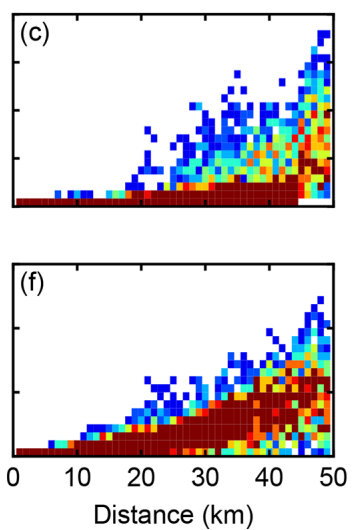

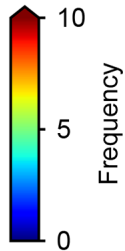

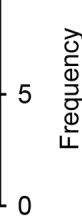

Figure 4. Spatial variability in glacial erosion $(\mathbf{a}-\mathbf{c})$ and percentage of time with warm basal ice (d-f). The $x$ axes are the distance from the left or right edge of the domain. The color scheme represents the frequency of pixels for a given combination of glacial erosion/percentage of time with warm basal ice and distance. Each column represents model results for a specific climate. The three climatic settings produce similar ELAs around $1300 \mathrm{~m}$. 


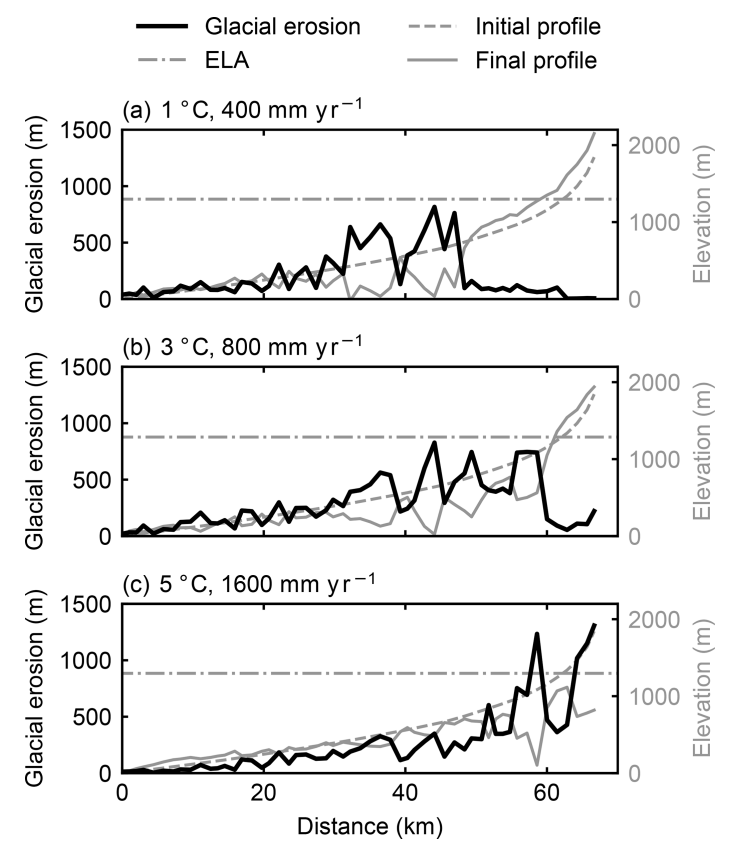

Figure 5. Glacial erosion (black lines), initial elevation (gray dashed lines) and finial elevation (gray solid lines) along a valley long profile. The location of the valley profile is shown as a red curve in Fig. 1a. Horizontal gray dash-dotted lines represent glacial ELAs. Although the glacial ELAs are similar in three cases, the spatial patterns of glacial erosion are different.

tion is strongly controlled by the air temperature. In a warm climate, glaciers are restricted to the upper part of the mountain range due to the relatively high ELA, while in cooler climates the majority of the mountain range is influenced by glaciation (Fig. 8).

Glaciers in a warm climate are mostly warm-based throughout the cycle, and most glacial erosion occurs at high elevations because high elevation regions are influenced by warm basal ice for a longer period than lower elevations (Figs. 8 and 10). As the climate transitions from a warm one into a cold one, it is commonly expected that the basal thermal regime at high elevations will shift from warm-based to cold-based. In our simulations, we observe such transition in basal thermal regime in relatively dry climates. In a dry and warm climate, the glaciers are mostly warm-based and are restricted within high-elevation regions, causing a small amount of glacial erosion primarily focusing on the center of the range (Fig. 8b). As the temperature decreases, glaciers at high elevations transition into cold-based conditions, resulting in limited glacial erosion (Fig. 8a). In contrast, in relatively wet climates, decreases in temperatures do not lead to a transition from warm-based to cold-based conditions (Fig. 8d-f). In a cold but relatively wet climate, highelevation regions are still covered by warm-based rather than cold-based glaciers, allowing for a great amount of erosion at high elevations (Fig. 8d). This indicates that the sensitiv- ities of glacier basal thermal regimes and glacial erosion to air temperature are dependent on the precipitation rates. A relatively wet climate could allow for warm-based areas at high elevations even in a cold climate. In the next section, we will further investigate the influence of precipitation on basal thermal regimes and glacial erosion.

\subsection{Sensitivity to precipitation}

We compare cases with different mean annual precipitation rates but the same air temperature at the glacial maximum. Increasing precipitation lowers the ELA by expanding the accumulation zone of glaciers. As expected, glaciers are smaller in a dry climate than in a wet climate, resulting in less glacial erosion (Figs. 9 and 10). There is a potential for a larger warm-based area in a wet climate than a dry climate because the thick ice in a wet climate lowers the melting point of ice and works to prevent the dissipation of heat accumulated at the base of ice. Increasing precipitation in cold climates allows warm-based ice to occur at increasingly high elevations. As a result, in cold climates, the area with significant erosion migrates into high elevations toward the center of the range as the climate becomes wetter (Fig. 9a-c) despite that the ELAs are lowered by high precipitation rates. In contrast, increasing precipitation in warm climates has little impact on the basal thermal regime because the glaciers are mostly warm-based already. In warm climates, glacial erosion constantly focuses at high elevations as the precipitation increases (Fig. 9d-f), although the glaciers become larger in a wetter climate.

\subsection{Synthesis-climatic controls on the spatial patterns of glacial erosion via basal thermal regime}

We quantify the spatial patterns of glacial erosion by identifying the "median location of erosion". For each simulation, we scan the eroded topography starting from both fronts of the mountain range until the scanned area consists of $50 \%$ of the total amount of glacial erosion. This location is described by the distance from the range fronts, and we refer to this distance as the "median location of erosion". The median location of erosion is greater (closer to the ridge center) for a simulation predicting that glacial erosion concentrates near the center of the mountain than a case in which glacial erosion focuses near the fronts of the mountain range.

The median location of erosion integrates the spatial distribution of glacial erosion into one single value and allows for a systemic comparison of glacial erosion patterns across the range of climatic scenarios explored in this study. In general, warm climates result in median locations of erosion that are closer to the center of the mountain range than cold climates (Fig. 10a), because warm climates lead to warm-based conditions in high-elevation regions and restrict the distribution of ice near the center of the mountain. The influence of precipitation on the spatial patterns of glacial erosion is also 

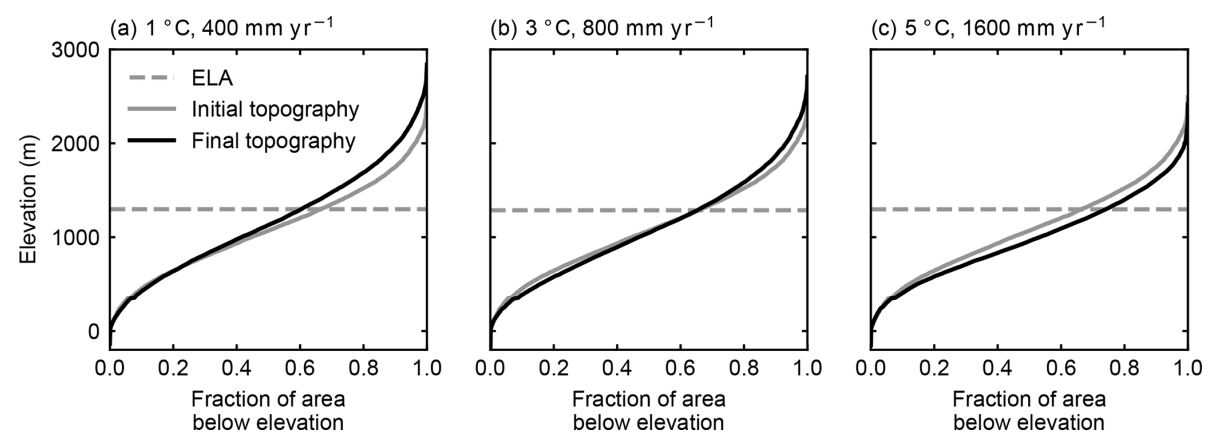

Figure 6. Hypsometric evolution of modeled landscapes in different climates. Initial topography is shown in gray solid lines and final topography is shown in black. Horizontal gray dashed lines indicate the ELAs.

$1^{\circ} \mathrm{C}, 400 \mathrm{~mm} \mathrm{yr}^{-1}$

(a)

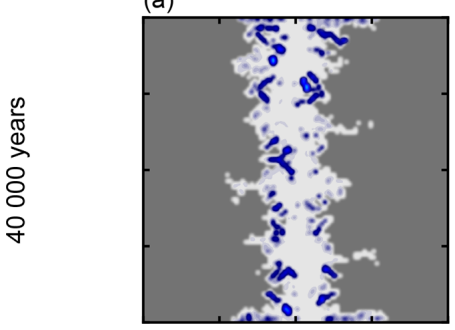

(d)
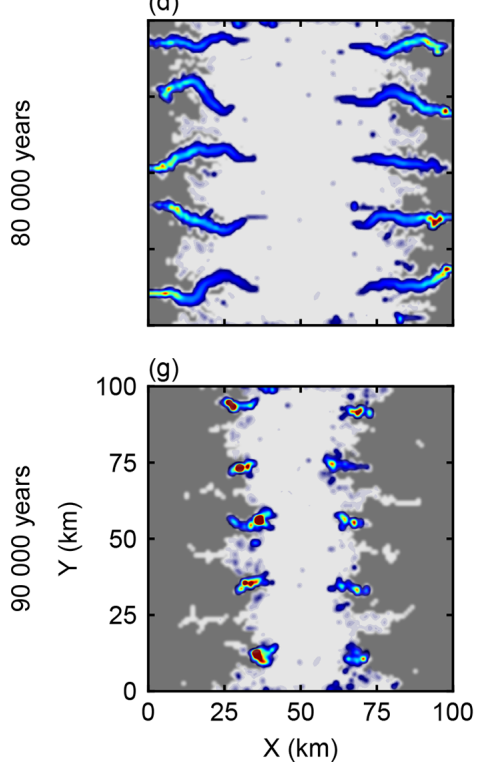

$3^{\circ} \mathrm{C}, 800 \mathrm{~mm} \mathrm{yr}^{-1}$

(b)

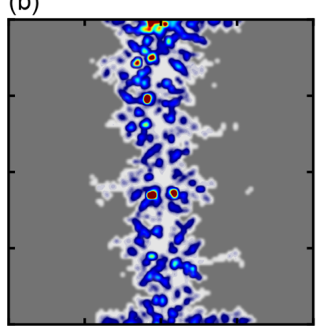

(e)

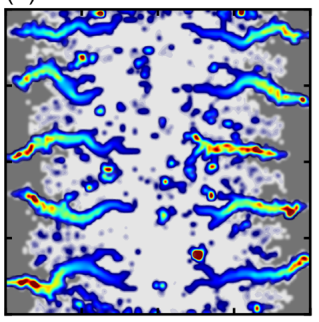

(h)

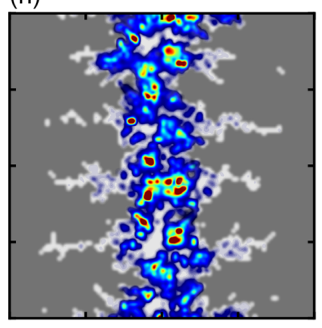

$5^{\circ} \mathrm{C}, 1600 \mathrm{~mm} \mathrm{yr}^{-1}$

(c)

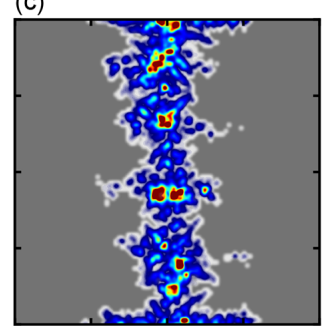

(f)

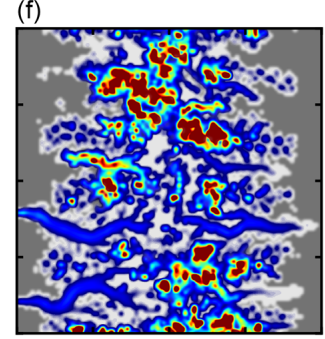

(i)

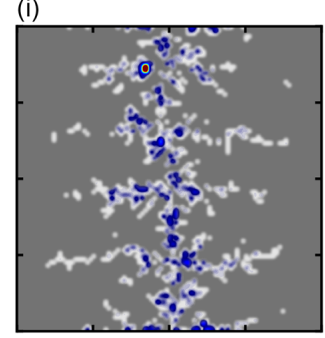

30

25

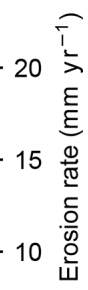

5

Figure 7. Average glacial erosion rates during three 1000-year windows (40000, 80000, and 90000 years after the simulation starts) for three cases with different climatic settings that produce similar ELAs around $1300 \mathrm{~m}$. Each column represents simulation results for a specific climate, and each row represents a time window. Ice-free areas are shown as dark gray.

revealed by the median location of erosion. In warm climates, the median locations of glacial erosion are close to the center of the mountain range, and as the precipitation increases, the median locations migrate slightly towards the edge of the mountain range due to increased glacially influenced area (Fig. 10a). A similar trend is also observed in cold climates when the precipitation is low. For example, when the mean annual temperature at sea level is $1{ }^{\circ} \mathrm{C}$ during glacial maximum, the median locations of glacial erosion also migrate toward the edge of the mountain range as precipitation rises up to $\sim 300 \mathrm{~mm} \mathrm{yr}^{-1}$. If the precipitation rates keep increasing, the median locations of glacial erosion will move towards the 

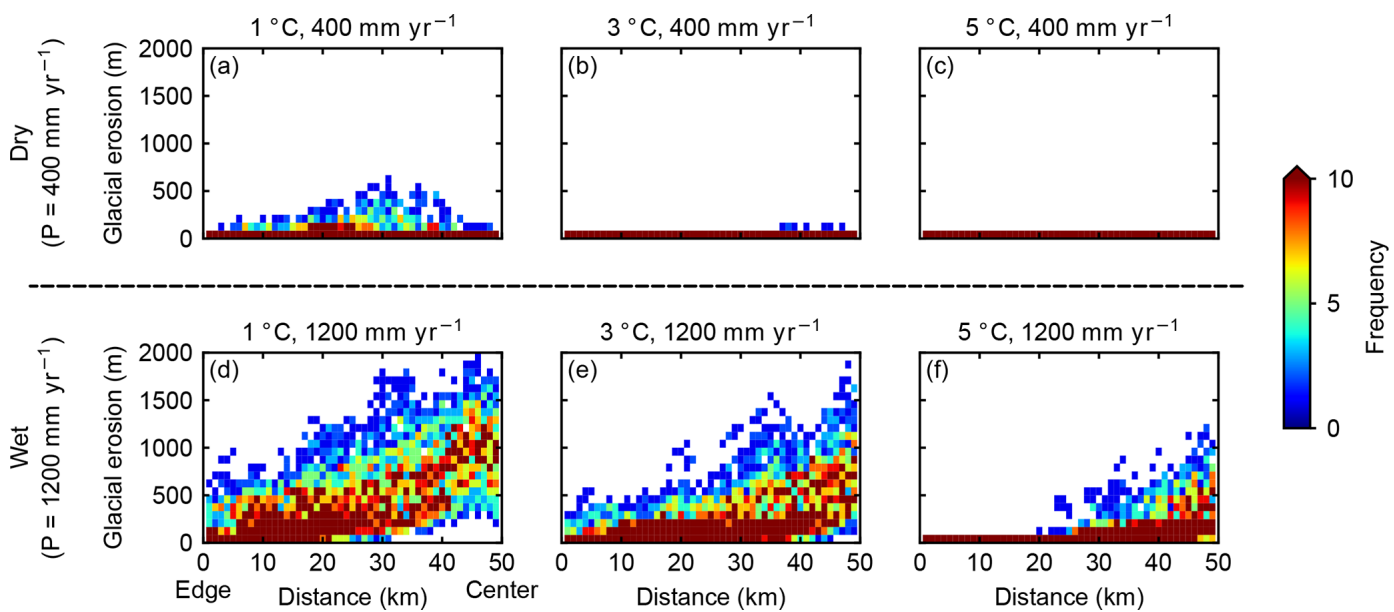

Figure 8. Influence of temperature on the spatial variability in glacial erosion. Each panel represents the result for a specific climate. (ac) The mean annual precipitation rate is $400 \mathrm{~mm} \mathrm{yr}^{-1}$ at glacial maximum in all three cases, and the mean annual sea-level temperatures are 1,3 , and $5^{\circ} \mathrm{C}$, respectively. (d-f) The mean annual precipitation rate is $1200 \mathrm{~mm} \mathrm{yr}^{-1}$ at glacial maximum in all three cases, and the mean annual sea-level temperatures are 1,3 , and $5^{\circ} \mathrm{C}$, respectively.
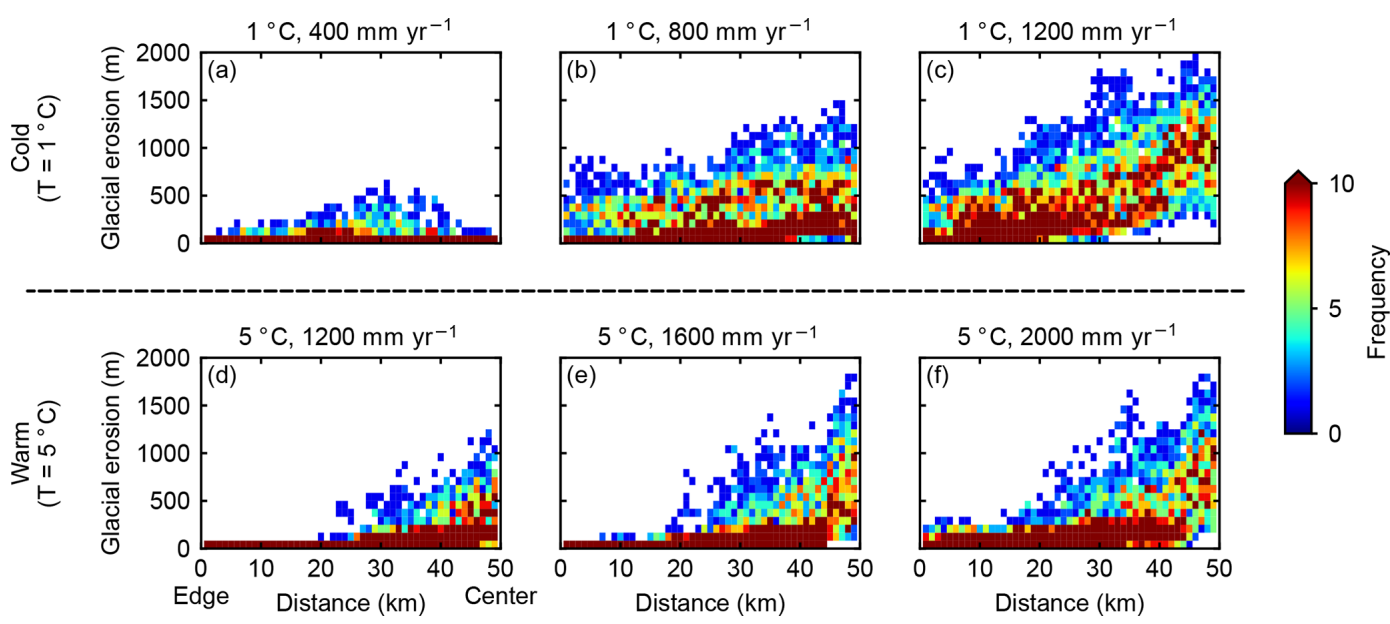

Figure 9. Influence of precipitation on the spatial variability in glacial erosion. Each panel represents the result for a specific climate. (ac) The mean annual sea-level temperature is $1^{\circ} \mathrm{C}$ at glacial maximum in all three cases, and the mean annual precipitation rates at glacial maximum are 400,800 , and $1200 \mathrm{~mm} \mathrm{yr}^{-1}$, respectively. (d-f) The mean annual sea-level temperature is $5^{\circ} \mathrm{C}$ at glacial maximum in all three cases, and the mean annual precipitation rates at glacial maximum are 1200,1600 , and $2000 \mathrm{~mm} \mathrm{yr}^{-1}$, respectively.

center of the mountain range because of the increased warmbased conditions at high elevations (Sect. 3.4; Fig. 10a-c). This finding suggests that the dependency of glacial erosion patterns on precipitation is more complicated in cold climates than warm climates.

We also summarize the ELAs and the fraction of warmbased area in glaciated regions during the glacial maximum for glaciation-only cases (Fig. 10b). The rates of glacial erosion are generally correlated with the fraction of warm-based area in glaciated regions. High fractions of warm-based areas correspond to fast rates of glacial erosion (Fig. 10a and b). The spatial patterns of glacial erosion reflected by the median location of glacial erosion do not always follow the pat- terns of ELAs. In warm climates, the ELAs are lowering as the precipitation rates increases, and both median locations of glacial erosion and the intersections between the ELA and the topography are migrating towards the front of the mountain range. However, in cold climates, as the precipitation rates increase, the median locations of erosion migrate towards the edge of the mountain range first, and then move back towards the center of the mountain range, while the ELAs are lowering constantly and the intersections of ELA and topography migrate towards the edge of the mountain range. The different sensitivities to climates between the spatial patterns of glacial erosion and the ELAs suggest that the 

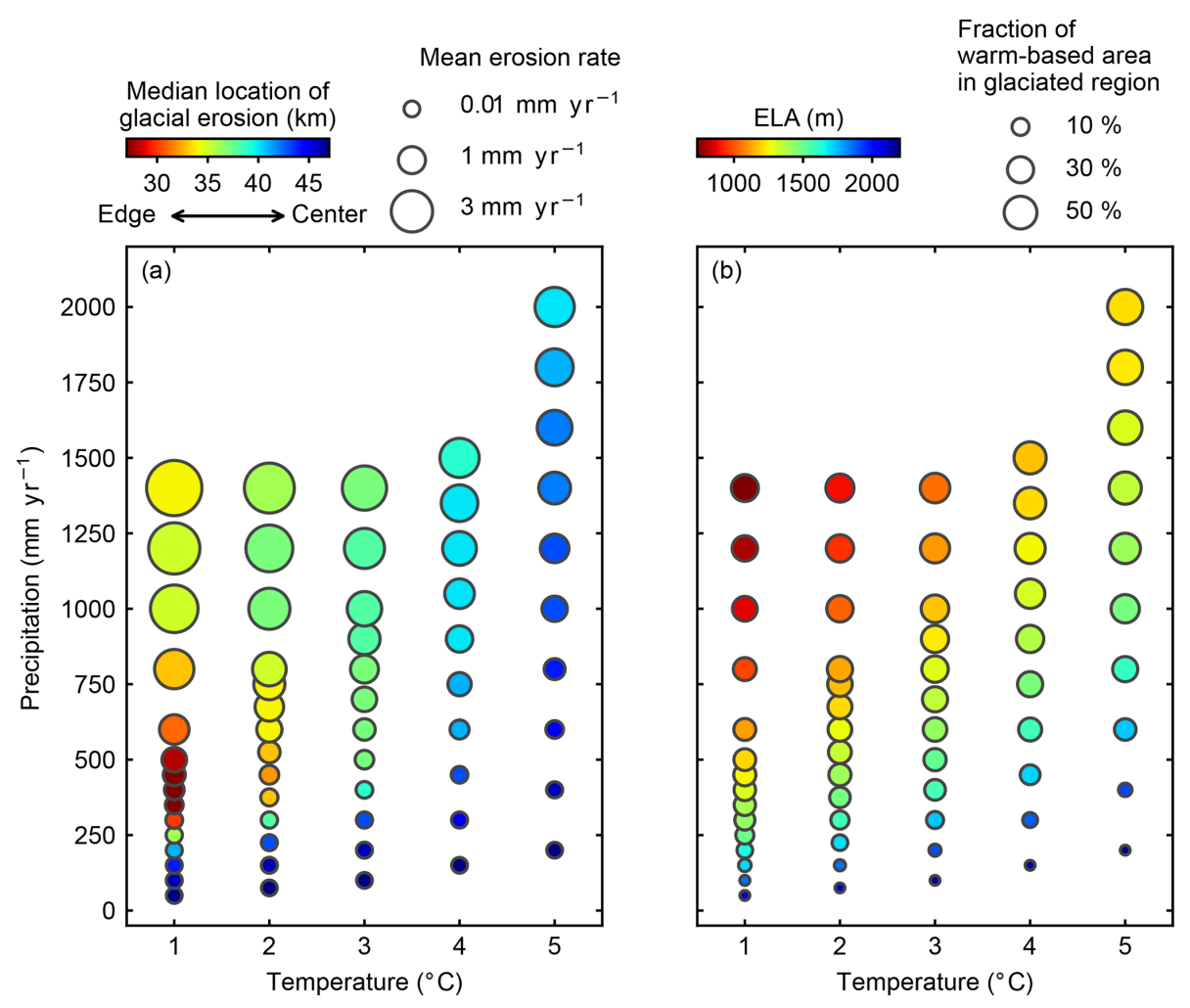

Figure 10. (a) The rates and median locations of glacial erosion in different climatic settings. Horizontal and vertical axes indicate the mean annual sea-level temperature and mean precipitation during the glacial maximum, respectively. The size of the circle represents the mean erosion rates in glaciated regions. The color scheme indicates the median locations of glacial erosion (see definition in Sect. 3.5). Red colors mean most erosion occurs near the edge of the mountain range, and blue colors represent that glacial erosion focuses near the center of the mountain range. (b) The ELAs and fraction of warm-based areas in glaciation-only cases in different climatic settings. Similarly, horizontal and vertical axes indicate climatic conditions. The size of the circle shows the fraction of warm-based area in glaciated regions during the glacial maximum, and the color scheme represents the ELAs during the glacial maximum.

spatial patterns of glacial erosion are not fully controlled by the ELAs, especially in cold climates.

\section{Discussion}

\subsection{ELA, basal thermal regime, and the location of maximum glacial erosion}

Previous studies of glacial erosion and glacial landscapes have emphasized the role of ELA in controlling the spatial patterns of erosion. The correlation between ELA and the spatial patterns of erosion partially arises from a simple framework: if we assume the rate of glacial erosion to first order scales with ice discharge (Anderson et al., 2006), then glacial erosion tends to focus around the ELA because ice discharge peaks at the ELA. Although ice discharge is a convenient proxy for erosion, many studies have shown that glacial erosion is controlled by sliding velocity (Hallet, 1979; Herman et al., 2015), subglacial hydrology (Beaud et al., 2014; Herman et al., 2011), and basal thermal regime (Koppes et al., 2015). In temperate glaciers with mostly warm basal ice, basal sliding occurs through- out the whole glacier, and therefore, basal sliding velocity scales, to first order, with ice discharge. Subglacial meltwater, however, tends to focus in the ablation zone and promotes sliding and erosion in low-elevation areas (Herman et al., 2011). The basal thermal regime is not correlated with ice discharge or ELA. Our previous work (Lai and Anders, 2020) showed that geothermal heat from the underlying bedrock can significantly change the basal thermal regime of glaciers without any changes in surface conditions, including the ELA. In this study, our numerical simulations show that the trade-off between temperature and precipitation could result in glaciers with similar ELAs but different basal thermal regimes (Fig. 2) as well as distinct patterns of glacial erosion (Figs. 3 and 4). Our results indicate that the patterns of glacial erosion are closely tied with the basal thermal regime rather than the ELA. Overall, based on our results and previous studies, we suggest that there might not be any direct spatial correlation between the ELA and the location of maximum erosion.

The observed agreement between mountain peak elevations and reconstructed past ELAs, i.e., the glacial buzz- 
saw hypothesis (Brozović et al., 1997; Egholm et al., 2009; Mitchell and Montgomery, 2006), suggests glaciers might focus their erosion at or above the ELAs. However, the past ELAs are often reconstructed using the cirque floor elevations (Mitchell and Montgomery, 2006; Porter, 1989, 2000), and they might represent the average glacial conditions rather than the actual ELA determined by a specific climate (Barr and Spagnolo, 2015; Porter, 1989). Cirques are formed over multiple glacial-interglacial cycles, and the development of a cirque is thought to primarily occur during periods with modest climate when the glacier is restricted within the cirque and is mostly warm-based (Barr and Spagnolo, 2015). The cirque floor elevations, therefore, are determined by the average intermediate conditions over multiple glacial-interglacial cycles (Barr and Spagnolo, 2015; Porter, 1989). As the cooling climate leads to more extensive glaciations, cirque enlargement might cease because the cirque is covered by cold-based ice, and the climatic conditions during these more extensive glaciation periods are not recorded in cirques. Our model results show that, although periods with extensive glaciation only occupy a short time interval of the whole glacial-interglacial cycle, the warm-based valley glaciers produce large amounts of erosion in major valleys during periods with extensive glaciation (Fig. 7). This observation from numerical simulations is also supported by the presence of widespread overdeepenings in glaciated mountain ranges (Magrani et al., 2020). For this reason, we suggest that cirque-based ELA estimates might not be an appropriate proxy for assessing the influence of past climate on glacial erosion, and their correlation with mountain peak elevations cannot support the idea that climate controls the spatial patterns of glacial erosion via changing ELAs. Observations of cirque floor elevation and cirque headwall relief suggest that cirques may set the base level for the hillslope processes that potentially limit the mountain peak elevations (Anders et al., 2010; Mitchell and Montgomery, 2006), and therefore, we speculate that the observed trend is the correlation between peak elevations and planes defined by cirque floors.

\subsection{Implication for understanding the sensitivity of glacial erosion to climate}

While precipitation has been viewed as the primary driver of fluvial incision (e.g., Ferrier et al., 2013) and hillslope erosion (e.g., Moon et al., 2011), the role of precipitation in controlling the rates and patterns of glacial erosion has received limited attention. In this work, we observe a wide range of glacial erosion rates as a function of precipitation. The rate of glacial erosion increases by 2 orders of magnitude as the precipitation rate rises by a factor of 5-10 (Fig. 10a). In cold conditions, increases in precipitation could change the basal thermal regime and cause a large amount of erosion at high elevations (Fig. 9a-c). Most previous studies focusing on the impact of climate on glacial erosion have put an emphasis on the role of temperature in lowering the ELAs and in con- trolling basal thermal regime (e.g., Thomson et al., 2010; Yanites and Ehlers, 2012). It is often suggested that glacial erosion is lower in cold, high-latitude regions because the cold temperature implies more frequent cold-based conditions. However, our simulations show that high precipitation rates could overcome the influence of cold temperature on the basal thermal regime by accumulating thick ice and lowering the melting point of ice. Precipitation also has the potential to promote basal sliding, glacial erosion, and the evacuation of sediments if the liquid water is able to reach the bed of glaciers (Cook et al., 2020; Herman et al., 2011; Koppes et al., 2015). The correlation between Quaternary erosion hotspots and precipitation maxima in the Patagonian Andes also suggests that precipitation exerts a first-order control on glacial erosion rates (Herman and Brandon, 2015). A recent global compilation of modern glacial erosion rates even suggests that precipitation explains more of the variability of modern erosion rates than temperature (Cook et al., 2020). Therefore, we suggest that precipitation should be viewed as equally important as temperature when assessing the influence of climate on glacial erosion.

Our simulations also show that increasing precipitation could result in a drop in the ELA, and this finding is consistent with field observations (Oien et al., 2020). However, in most previous glacial landscape evolution models, precipitation is often integrated into the mass balance term or changes as a function of temperature, and the impact of precipitation on the ELA is not explicitly modeled (e.g., Yanites and Ehlers, 2012). We suggest that precipitation should be viewed as an independent component in glacial landscape evolution models.

Koppes et al. (2015) observed significant latitudinal variation of contemporary glacial erosion rates in Patagonia and the Antarctic Peninsula, and they suggested that a mean annual temperature around $0-5{ }^{\circ} \mathrm{C}$ might represent a threshold condition for fast glacial erosion due to shifts between coldbased to warm-based conditions. In our work, the explored range of the mean annual sea-level temperatures lies in this threshold range, but our results do not show a significant increase in glacial erosion rates as mean annual temperatures increase from 1 to $5^{\circ} \mathrm{C}$ (Fig. 10a). Instead, our numerical simulations predict that climates with low temperatures and high precipitation rates are optimal conditions for glacial erosion (Fig. 10a). A recent global compilation of modern erosion rates also shows a pattern of high glacial erosion rates in similar climatic conditions (Cook et al., 2020). This is probably because the glaciers surveyed by Koppes et al. (2015) are all large outlet tidewater glaciers with similar catchment sizes, while in our simulations, the sizes of glaciers are highly variable. For example, in a warm and dry climate, the sizes of ice bodies are not large enough to form fast-flowing valley glaciers, and as a result, the rates of glacial erosion are limited (Fig. 8c; the lower right corner in Fig. 10a). If we compare cases with similar ELAs, which imply similar glacier sizes, our results indeed show an increasing trend of glacial 
erosion rates as mean annual temperatures rise (Figs. 4 and $10)$, although the amount of increase in glacial erosion predicted by our model (10-fold) is less than the over 100-fold difference observed by Koppes et al. (2015). Importantly, our results support the idea of Koppes et al. (2015) that glacial erosion is highly variable in a relatively narrow range of climates as a result of changes in basal thermal regime.

The temporal evolution of glacial erosion rates inferred from sedimentary records suggests that the response of glacial erosion to climate forcing is nonlinear and that glacial erosion preferentially occurs during short periods with optimal climatic conditions (Fernandez et al., 2011; Ganti et al., 2016; Mariotti et al., 2021). Mariotti et al. (2021) suggest that such nonlinear forcing of climate is a result of the complex interplay between glacier sliding velocity and topography. In this study, our simulations predict a wide range of glacial erosion rates due to the climatically controlled basal thermal regime, and a cold and wet climate is the optimal condition for rapid glacial erosion. This finding provides an alternative mechanism for the nonlinear relationship between glacial erosion and climate. The highly variable erosion rates also provide implications for the ongoing debate on the potential global increase in erosion rates in response to widespread glaciations during the Pleistocene (Herman et al., 2013; Herman and Champagnac, 2016; Willenbring and Jerolmack, 2016). Our results suggest that, due to the variation of basal thermal regimes in different climatic settings, glaciations in cold and dry regions do not necessarily induce rapid glacial erosion.

\section{Conclusions}

In this study, we investigate the impact of climatic conditions on the basal thermal regime of glaciers and glacial erosion patterns, using a landscape evolution model coupled with an ice sheet model. Our results indicate that the spatial patterns of glacial erosion follow the patterns of the basal thermal regime. Cold temperatures create cold-based glacier areas at high elevations, while high precipitation rates tend to cause warm-based conditions by increasing the thickness of glaciers and lowering the melting point of ice. Glaciers in a cold and dry climate have limited erosion at high elevations due to cold-based conditions, and most glacial erosion focuses at low elevations in major valleys. By contrast, a warm and wet climate causes a large amount of erosion at high elevations. Our results do not support the direct correlation between the ELA and the patterns of glacial erosion, because different temperature and precipitation combinations could produce glaciers with similar ELAs but distinct basal thermal regimes. Our study provides a mechanistic basis for the relationship between climate and glacial erosion, and it reinforces the interactions between climate and erosional processes.
Code availability. The version of PISM used in this study is available at https://doi.org/10.5281/zenodo.5142298 (Khrulev et al., 2021).

Author contributions. JL and AMA designed the experiments, and JL developed code and conducted the experiments. Both authors contributed to data analysis. JL prepared the manuscript with inputs from AMA.

Competing interests. The authors declare that they have no conflict of interest.

Disclaimer. Publisher's note: Copernicus Publications remains neutral with regard to jurisdictional claims in published maps and institutional affiliations.

Acknowledgements. We are grateful to Andy Aschwanden and Jonathan Tomkin for their constructive comments on multiple drafts of the manuscript. We thank Simon Cook and Ian Delaney for their constructive review.

Review statement. This paper was edited by Michele Koppes and reviewed by Simon Cook and Ian Delaney.

\section{References}

Anders, A. M., Mitchell, S. G., and Tomkin, J. H.: Cirques, peaks, and precipitation patterns in the Swiss Alps: Connections among climate, glacial erosion, and topography, Geology, 38, 239-242, https://doi.org/10.1130/G30691.1, 2010.

Anderson, R. S., Molnar, P., and Kessler, M. A.: Features of glacial valley profiles simply explained, J. Geophys. Res., 111, F01004, https://doi.org/10.1029/2005JF000344, 2006.

Anderson, R. S., Dühnforth, M., Colgan, W., and Anderson, L.: Far-flung moraines: Exploring the feedback of glacial erosion on the evolution of glacier length, Geomorphology, 179, 269-285, https://doi.org/10.1016/j.geomorph.2012.08.018, 2012.

Aschwanden, A., Bueler, E., Khroulev, C., and Blatter, H.: An enthalpy formulation for glaciers and ice sheets, J. Glaciol., 58, 441-457, https://doi.org/10.3189/2012JoG11J088, 2012.

Aschwanden, A., Fahnestock, M. A., and Truffer, M.: Complex Greenland outlet glacier flow captured, Nat. Commun., 7, 1-8, https://doi.org/10.1038/ncomms10524, 2016.

Barr, I. D. and Spagnolo, M.: Glacial cirques as palaeoenvironmental indicators: Their potential and limitations, Earth-Sci. Rev., 151, 48-78, https://doi.org/10.1016/j.earscirev.2015.10.004, 2015.

Beaud, F., Flowers, G. E., and Pimentel, S.: Seasonal-scale abrasion and quarrying patterns from a two-dimensional ice-flow model coupled to distributed and channelized subglacial drainage, Geomorphology, 219, 176-191, https://doi.org/10.1016/j.geomorph.2014.04.036, 2014. 
Braun, J. and Willett, S. D.: A very efficient $\mathrm{O}(n)$, implicit and parallel method to solve the stream power equation governing fluvial incision and landscape evolution, Geomorphology, 180181, 170-179, https://doi.org/10.1016/j.geomorph.2012.10.008, 2013.

Brozović, N., Burbank, D. W., and Meigs, A. J.: Climatic limits on landscape development in the Northwestern Himalaya, Science, 276, 571-574, https://doi.org/10.1126/science.276.5312.571, 1997.

Bueler, E. and Brown, J.: Shallow shelf approximation as a "sliding law" in a thermomechanically coupled ice sheet model, J. Geophys. Res.-Sol. Ea., 114, 1-21, https://doi.org/10.1029/2008JF001179, 2009.

Calov, R. and Greve, R.: A semi-analytical solution for the positive degree-day model with stochastic temperature variations, J. Glaciol., 51, 173-175, https://doi.org/10.3189/172756505781829601, 2005.

Cook, S. J., Swift, D. A., Kirkbride, M. P., Knight, P. G., and Waller, R. I.: The empirical basis for modelling glacial erosion rates, Nat. Commun., 11, 759, https://doi.org/10.1038/s41467020-14583-8, 2020.

Egholm, D. L., Nielsen, S. B., Pedersen, V. K., and Lesemann, J.-E.: Glacial effects limiting mountain height, Nature, 460, 884-887, https://doi.org/10.1038/nature08263, 2009.

Egholm, D. L., Knudsen, M. F., Clark, C. D., and Lesemann, J. E.: Modeling the flow of glaciers in steep terrains: The integrated second-order shallow ice approximation (iSOSIA), J. Geophys. Res.-Earth, 116, 1-16, https://doi.org/10.1029/2010JF001900, 2011.

Fernandez, R. A., Anderson, J. B., Wellner, J. S., and Hallet, B.: Timescale dependence of glacial erosion rates: A case study of Marinelli Glacier, Cordillera Darwin, southern Patagonia, J. Geophys. Res.-Earth, 116, F01020, https://doi.org/10.1029/2010JF001685, 2011.

Ferrier, K. L., Huppert, K. L., and Perron, J. T.: Climatic control of bedrock river incision, Nature, 496, 206-209, https://doi.org/10.1038/nature11982, 2013.

Ganti, V., Hagke, C. Von, Scherler, D., Lamb, M. P., Fischer, W. W., and Avouac, J.: Time scale bias in erosion rates of glaciated landscapes, Sci. Adv., 2, e1600204, https://doi.org/10.1126/sciadv.1600204, 2016.

Golledge, N. R., Mackintosh, A. N., Anderson, B. M., Buckley, K. M., Doughty, A. M., Barrell, D. J. A., Denton, G. H., Vandergoes, M. J., Andersen, B. G., and Schaefer, J. M.: Last Glacial Maximum climate in New Zealand inferred from a modelled Southern Alps icefield, Quaternary Sci. Rev., 46, 30-45, https://doi.org/10.1016/j.quascirev.2012.05.004, 2012.

Hall, A. M., Ebert, K., Kleman, J., Nesje, A., and Ottesen, D.: Selective glacial erosion on the Norwegian passive margin, Geology, 41, 1203-1206, https://doi.org/10.1130/G34806.1, 2013.

Hallet, B.: A Theoretical Model of Glacial Abrasion, J. Glaciol., 23, 39-50, https://doi.org/10.1017/S0022143000029725, 1979.

Hallet, B.: Glacial quarrying: a simple theoretical model, Ann. Glaciol., 22, 1-8, https://doi.org/10.3189/1996AoG22-1-1-8, 1996.

Harel, M.-A., Mudd, S. M., and Attal, M.: Global analysis of the stream power law parameters based on worldwide $10 \mathrm{Be}$ denudation rates, Geomorphology, 268, 184-196, https://doi.org/10.1016/j.geomorph.2016.05.035, 2016.
Herman, F. and Brandon, M.: Mid-latitude glacial erosion hotspot related to equatorial shifts in southern Westerlies, Geology, 43, 987-990, https://doi.org/10.1130/G37008.1, 2015.

Herman, F. and Braun, J.: Evolution of the glacial landscape of the Southern Alps of New Zealand: Insights from a glacial erosion model, J. Geophys. Res.-Earth, 113, F02009, https://doi.org/10.1029/2007JF000807, 2008.

Herman, F. and Champagnac, J. D.: Plio-Pleistocene increase of erosion rates in mountain belts in response to climate change, Terra Nova, 28, 2-10, https://doi.org/10.1111/ter.12186, 2016.

Herman, F., Beaud, F., Champagnac, J. D., Lemieux, J. M., and Sternai, P.: Glacial hydrology and erosion patterns: A mechanism for carving glacial valleys, Earth Planet. Sc. Lett., 310, 498-508, https://doi.org/10.1016/j.epsl.2011.08.022, 2011.

Herman, F., Seward, D., Valla, P. G., Carter, A., Kohn, B., Willett, S. D., and Ehlers, T. a.: Worldwide acceleration of mountain erosion under a cooling climate, Nature, 504, 423-426, https://doi.org/10.1038/nature12877, 2013.

Herman, F., Beyssac, O., Brughelli, M., Lane, S. N., Leprince, S., Adatte, T., Lin, J. Y. Y., Avouac, J.-P., and Cox, S. C.: Erosion by an Alpine glacier, Science, 350, 193-195, https://doi.org/10.1126/science.aab2386, 2015.

Hindmarsh, R. C. A.: The role of membrane-like stresses in determining the stability and sensitivity of the Antarctic ice sheets: back pressure and grounding line motion, Philos. T. R. Soc. A, 364, 1733-1767, https://doi.org/10.1098/rsta.2006.1797, 2006.

Hobley, D. E. J., Adams, J. M., Nudurupati, S. S., Hutton, E. W. H., Gasparini, N. M., Istanbulluoglu, E., and Tucker, G. E.: Creative computing with Landlab: an open-source toolkit for building, coupling, and exploring two-dimensional numerical models of Earth-surface dynamics, Earth Surf. Dynam., 5, 21-46, https://doi.org/10.5194/esurf-5-21-2017, 2017.

Humphrey, N. F. and Raymond, C. F.: Hydrology, erosion and sediment production in a surging glacier: Variegated Glacier, Alaska, 1982-83, J. Glaciol., 40, 539-552, https://doi.org/10.3189/S0022143000012429, 1994.

Hutter, K.: Theoretical Glaciology, D. Reidel Publishing Company, Dordrecht, the Netherlands, 1983.

Huybrechts, P.: Sea-level changes at the LGM from ice-dynamic reconstructions of the Greenland and Antarctic ice sheets during the glacial cycles, Quaternary Sci. Rev., 21, 203-231, https://doi.org/10.1016/S0277-3791(01)00082-8, 2002.

Iverson, N. R.: A theory of glacial quarrying for landscape evolution models, Geology, 40, 679-682, https://doi.org/10.1130/G33079.1, 2012.

Khrulev, C., Bueler, E., Maxwell, D., Aschwanden, A., Brown, J., Albrecht, T., Seguinot, J., Mengel, M., Ziemen, F., Kleiner, T., Kennedy, J. H., Mccarthy, A. K., and Reese, R.: laijingtao/pism: (jlai-Esurf-2021) [code], Zenodo, https://doi.org/10.5281/zenodo.5142298, 2021.

Kleman, J. and Glasser, N. F.: The subglacial thermal organisation (STO) of ice sheets, Quaternary Sci. Rev., 26, 585-597, https://doi.org/10.1016/j.quascirev.2006.12.010, 2007.

Koppes, M., Hallet, B., Rignot, E., Mouginot, J., Wellner, J. S., and Boldt, K.: Observed latitudinal variations in erosion as a function of glacier dynamics, Nature, 526, 100-103, https://doi.org/10.1038/nature15385, 2015.

Lai, J. and Anders, A. M.: Modeled Postglacial Landscape Evolution at the Southern Margin of the Laurentide Ice Sheet: Hydro- 
logical Connection of Uplands Controls the Pace and Style of Fluvial Network Expansion, J. Geophys. Res.-Earth, 123, 967984, https://doi.org/10.1029/2017JF004509, 2018.

Lai, J. and Anders, A. M.: Tectonic controls on rates and spatial patterns of glacial erosion through geothermal heat flux, Earth Planet. Sc. Lett., 543, 116348, https://doi.org/10.1016/j.eps1.2020.116348, 2020.

MacGregor, K. R., Anderson, R. S., Anderson, S. P., and Waddington, E. D.: Numerical simulations of glacial-valley longitudinal profile evolution, Geology, 28, 1031-1034, https://doi.org/10.1130/00917613(2000)028<1031:NSOGVL>2.3.CO;2, 2000.

Magrani, F., Valla, P. G., Gribenski, N., and Serra, E.: Glacial overdeepenings in the Swiss Alps and foreland: Spatial distribution and morphometrics, Quaternary Sci. Rev., 243, 106483, https://doi.org/10.1016/j.quascirev.2020.106483, 2020.

Mariotti, A., Blard, P.-H., Charreau, J., Toucanne, S., Jorry, S. J., Molliex, S., Bourlès, D. L., Aumaître, G., and Keddadouche, K.: Nonlinear forcing of climate on mountain denudation during glaciations, Nat. Geosci., 14, 16-22, https://doi.org/10.1038/s41561-020-00672-2, 2021.

Mitchell, S. G. and Montgomery, D. R.: Influence of a glacial buzzsaw on the height and morphology of the Cascade Range in central Washington State, USA, Quaternary Res., 65, 96-107, https://doi.org/10.1016/j.yqres.2005.08.018, 2006.

Moon, S., Page Chamberlain, C., Blisniuk, K., Levine, N., Rood, D. H., and Hilley, G. E.: Climatic control of denudation in the deglaciated landscape of the Washington Cascades, Nat. Geosci., 4, 469-473, https://doi.org/10.1038/ngeo1159, 2011.

Morland, L. W.: Unconfined Ice-Shelf Flow, in Dynamics of the West Antarctic Ice Sheet, edited by C. J. van der Veen and J. Oerlemans, pp. 99-116, D. Reidel Publishing Company, Dordrecht, the Netherlands, 1987.

Oien, R. P., Spagnolo, M., Rea, B. R., Barr, I. D., and Bingham, R. G.: Climatic controls on the equilibrium-line altitudes of Scandinavian cirque glaciers, Geomorphology, 352, 106986, https://doi.org/10.1016/j.geomorph.2019.106986, 2020.

Porter, S. C.: Some Geological Implications of Average Quaternary Glacial Conditions, Quaternary Res., 32, 245-261, https://doi.org/10.1016/0033-5894(89)90092-6, 1989.

Porter, S. C.: Snowline depression in the tropics during the Last Glaciation, Quaternary Sci. Rev., 20, 1067-1091, https://doi.org/10.1016/S0277-3791(00)00178-5, 2000.
Prasicek, G., Herman, F., Robl, J., and Braun, J.: Glacial Steady State Topography Controlled by the Coupled Influence of Tectonics and Climate, J. Geophys. Res.-Earth, 123, 1344-1362, https://doi.org/10.1029/2017JF004559, 2018.

Seguinot, J. and Delaney, I.: Last glacial cycle glacier erosion potential in the Alps, Earth Surf. Dynam. Discuss. [preprint], https://doi.org/10.5194/esurf-2021-12, in review, 2021.

Seguinot, J., Ivy-Ochs, S., Jouvet, G., Huss, M., Funk, M., and Preusser, F.: Modelling last glacial cycle ice dynamics in the Alps, The Cryosphere, 12, 3265-3285, https://doi.org/10.5194/tc-12-3265-2018, 2018.

Thomson, S. N., Brandon, M. T., Tomkin, J. H., Reiners, P. W., Vásquez, C., and Wilson, N. J.: Glaciation as a destructive and constructive control on mountain building, Nature, 467, 313317, https://doi.org/10.1038/nature09365, 2010.

Tomkin, J. H. and Braun, J.: The influence of alpine glaciation on the relief of tectonically active mountain belts, Am. J. Sci., 302, 169-190, https://doi.org/10.2475/ajs.302.3.169, 2002.

Ugelvig, S. V, Egholm, D. L., and Iverson, N. R.: Glacial landscape evolution by subglacial quarrying: A multiscale computational approach, J. Geophys. Res.-Earth, 121, 2042-2068, https://doi.org/10.1002/2016JF003960, 2016.

Whipple, K. X. and Tucker, G. E.: Dynamics of the streampower river incision model: Implications for height limits of mountain ranges, landscape response timescales, and research needs, J. Geophys. Res.-Sol. Ea., 104, 17661-17674, https://doi.org/10.1029/1999JB900120, 1999.

Willenbring, J. K. and Jerolmack, D. J.: The null hypothesis: Globally steady rates of erosion, weathering fluxes and shelf sediment accumulation during Late Cenozoic mountain uplift and glaciation, Terra Nova, 28, 11-18, https://doi.org/10.1111/ter.12185, 2016.

Winkelmann, R., Martin, M. A., Haseloff, M., Albrecht, T., Bueler, E., Khroulev, C., and Levermann, A.: The Potsdam Parallel Ice Sheet Model (PISM-PIK) - Part 1: Model description, The Cryosphere, 5, 715-726, https://doi.org/10.5194/tc-5-715-2011, 2011.

Yanites, B. J. and Ehlers, T. A.: Global climate and tectonic controls on the denudation of glaciated mountains, Earth Planet. Sc. Lett., 325-326, 63-75, https://doi.org/10.1016/j.epsl.2012.01.030, 2012. 